\title{
PERAN CITRA MEREK DAN PENGARUHNYA TERHADAP EKUITAS MEREK HANDPHONE SAMSUNG
}

\author{
Dinan \\ Email : dinan@gmail.com \\ STIE Palangkayara
}

\begin{abstract}
This research has background the phenomena of brand competition of various companies in obtaining Top Brand Award. Customers tend to give more trust at any brands that have once achieved the Top Brand Award. Decreased top brand index indicates problems on brand equity of the Handphone Samsung. The problem in this research is "What is Brand Image and Brand Awareness effect on Brand Equity of Samsung Handphone". Brand image and brand awareness are assumed to have effects on brand equity and greatly importance to build strong brand equity. Therefore, this research aims to analyze the effects of Brand Image and Brand Awareness on Brand Equity of Samsung Handphone.

This research used 10 respondents as the samples who have purchased Samsung Handphone with purposive sample and accidental samples. Then, there was data analysis both quantitatively and qualitatively. The qualitative analysis is the interpretation of data that were obtained in the field and open answer analysis given by the respondents, while quantitative analysis includes: reliability test, validity test, classical assumption test, multiple linear regression analysis, $\mathrm{F}$ test, $\mathrm{t}$ test and determination coefficient analysis $(\mathrm{X})$.

Results of this research indicate that brand image (X1) and brand awareness (X2) are proven to significantly affect the brand equity (Y). Out of two analyzed independent variables, the brand awareness is the variables with the biggest effects on the dependent variable, which then is followed by the brand image.
\end{abstract}

Keywords: Brand Image, Brand Awareness, and Brand Equity

\section{PENDAHULUAN}

Di pasar yang serba kompetitif seperti sekarang ini, merek mempunyai peranan penting bagi kelangsungan hidup sebuah perusahaan. Apalagi pemasaran di masa yang akan datang lebih menjadi persaingan antar merek, yaitu persaingan untuk merebut konsumen melalui merek. Selain itu merek bukan hanya dianggap sebagai sebuah nama, logo ataupun simbol. Lebih dari itu merek merupakan nilai yang ditawarkan sebuah produk bagi konsumen yang memakainya.

Merek dapat memberikan manfaat yang besar bagi produsen 
maupun konsumen. Bagi konsumen merek mampu menambah nilai bagi konsumen. Dimana adanya persepsi dan keyakinan atas produk yang menyebabkan konsumen ingin terasosiasikan dan membelinya, sehingga konsumen tidak segan membayar mahal untuk mendapatkan produk dengan merek tertentu.

Konsumen bersedia membayar lebih tinggi suatu produk karena melekat padanya merek yang merupakan jaminan kosistensi kualitas dan nilai tertentu yang diyakini terkandung didalamnya, tanpa adanya merek konsumen menjadi kurang merasa aman dari kemungkinan buruk diluar harapan. Seperti yang diungkapkan oleh Kenapp (2001) bahwa tujuan utama dari merek sejati adalah untuk menambah nilai manusia. Selanjutnya Kenapp (2001) menyatakan bahwa merek sejati adalah tentang memberi manfaat kepada pelanggan dan merek yang terdiferensiasi lebih mudah untuk dikomunikasikan secara efisien kepada konsumen.

Pada kenyatannya sebuah merek memang sudah dianggap sebagai aset (equity) oleh sebuah perusahaan atau yang lebih dikenal dengan istilah ekuitas merek (Kotler, 2005).

Selanjutnya Aaker

memandang ekuitas merek sebagai suatu perangkat dari lima kategori aset yang terdiri dari : (1) kesetiaan merek (brand loyality), (2) kesadaran merek (brand awareness), (3) mutu yang dirasakan (perceived quality), asosiasi merek (brand association), dan (5) aset kepemilikan lainnya (property brand assets) seperti pola, merek dagang dan saluran distribusi. Kesadaran merek merupakan elemen kunci dalam generasi ekuitas merek seperti yang diungkapkan oleh Villarejo, et al (2008) bahwa "Brand awareness is a key element in the generation of brand equity". Selanjutnya Kartajaya (2006) menyatakan pembentukan citra merek merupakan upaya kritis dalam membangun ekuitas merek. Sebab citra itulah yang ditangkap dan dipercaya oleh benak konsumen.

Karena itu Kartajaya, (2006) lantas memberi empat kategori asosiasi-asosiasi merek yang bisa dibentuk yaitu: brand as a product, brand as an organization, brand as a person dan brand a symbol. Melalui citra merek yang kuat, maka pelanggan akan memiliki asumsi 
positif terhadap merek dari produk yang ditawarkan oleh perusahaan sehingga konsumen tidak akan ragu untuk membeli produk yang akan ditawarkan perusahaan.

Citra merek menjadi hal yang sangat penting diperhatikan perusahaan, melalui citra merek yang baik, maka dapat menimbulkan nilai emosional pada diri konsumen, dimana akan timbulnya perasaan positif (positive feeling) pada saat membeli atau menggunakan suatu merek. Demikian sebaliknya apabila suatu merek memiliki citra (image) yang buruk dimata konsumen kecil kemungkinan konsumen untuk membeli produk tersebut.

Penelitian ini bertujuan untuk menganalisis (1) Peran citra merek erhadap ekuitas merek Hendphone Samsung (2) Pengaruh kesadaran merek terhadap ekuitas merek Hendphone Samsung.

\section{TINJAUAN PUSTAKA}

\section{Merek}

Definisi merek menurut Asosiasi Pemasaran Amerika adalah suatu nama, istilah, tanda, simbol, atau rancangan, atau kombinasi dari semuanya yang dimaksudkan untuk mengidentifikasi barang atau jasa penjual atau kelompok penjual dan untuk mendiferensiasikannya dari produk atau jasa lain yang dirancang untuk memuaskan kebutuhan yang sama (Kotler dan Keller, 2007).

Kotler (2005) menambahkan bahwa suatu merek adalah suatu simbol komplek yang menjelaskan enam tingkatan pengertian, yaitu (a.) Atribut : merek memberikan ingatan pada atribut-atribut tertentu dari suatu produk (b) Manfaat : atribut-atribut produk yang dapat diingat melalui merek harus dapat diterjemahkan dalam bentuk manfaat baik secara fungsional dan manfaat secara emosional (3). Nilai: merek mencerminkan nilai yang dimiliki oleh produsen sebuah produk (4). Budaya: merek mempresentasikan suatu budaya tertentu (4).Kepribadian : merek dapat memproyeksikan pada suatu kepribadian tertentu. (5) Pengguna: merek mengelompokan tipetipe konsumen yang akan membeli atau mengkonsumsi suatu produk. 
Gambar 1

Lima Dimensi Pembentuk Ekuitas Merek

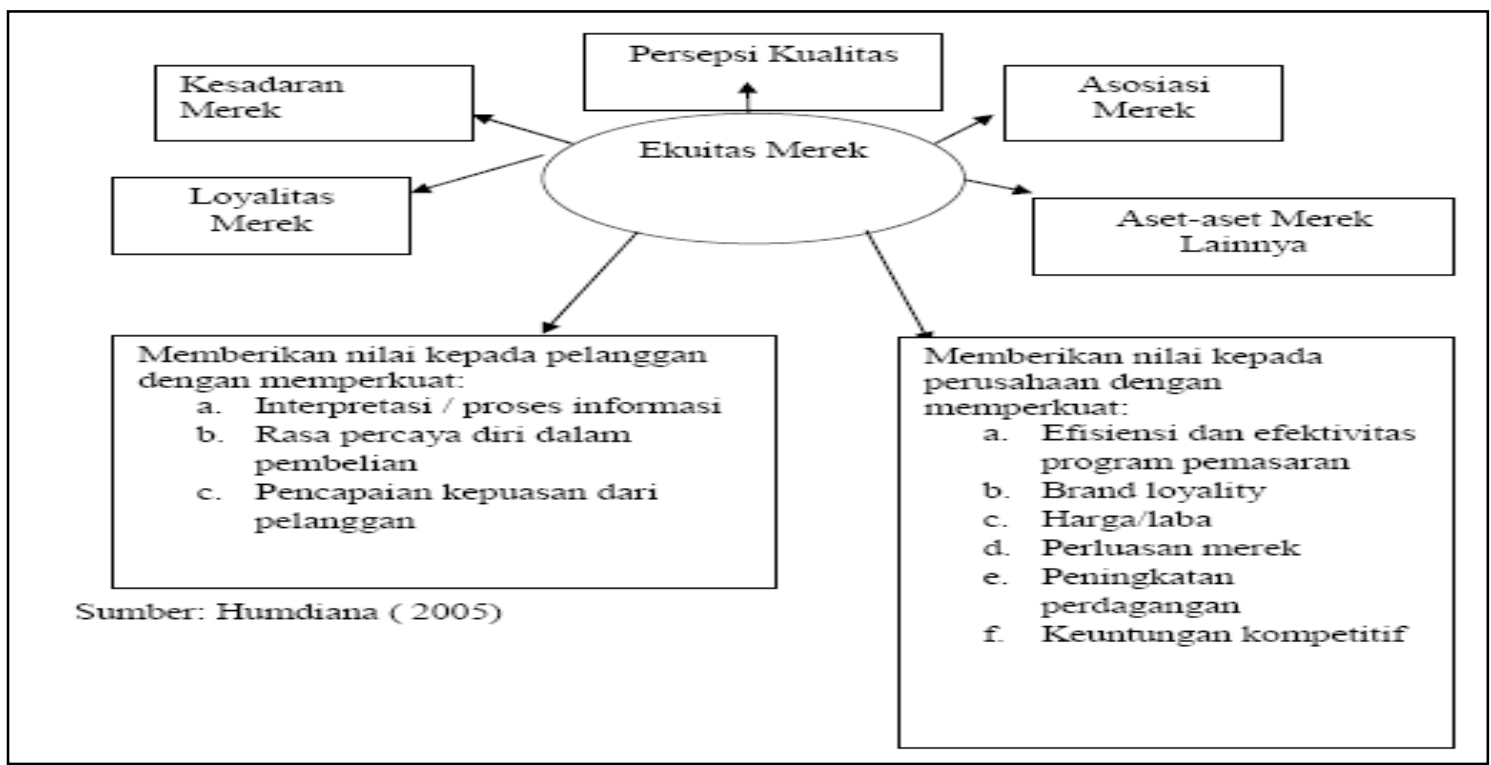

Sumber: Humdiana (2005)

Membangun kesadaran merek (brand awareness) biasanya dilkakukan dalam periode waktu yang lama karena penghafalan bisa berhasil dengan repetisi dan penguatan. Dalam kenyataan merek-merek dengan tingkat pengingatan kembali yang tinggi biasanya merupakan merek-merek yang berusia tua (Humdiana, 2005).

Hubungan antara Kesadaran Merek (Brand Awerness) dengan Ekuitas Merek (Brand Equity). Kesadaran merek merupakan elemen kunci dalam generasi ekuitas merek seperti yang diungkapkan oleh Villarejo, et al (2008) bahwa "Brand awareness is a key element in the generation of brand equity". Berdasarkan pemikiran tersebut, hipotesis berikut disajikan : $\mathrm{H}$ : Kesadaran merek (X) memiliki pengaruh yang positif terhadap ekuitas merek (Y). 


\section{Kerangka Pemikiran}

Kerangka pemikiran dalam penelitian ini adalah sebagaimana tersaji dalam gambar 2 berikut ini.

Gambar 2

Kerangka Pemikiran

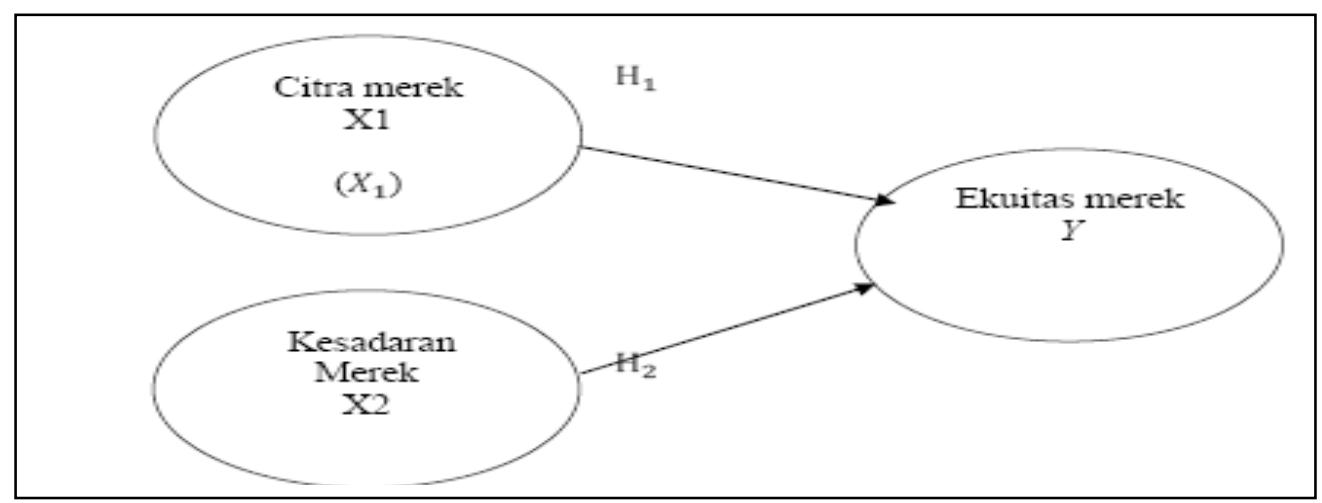

Sumber: Konsep yang dikembangkan untuk penelitian ini , 2018

\section{Hipotesis}

Hipotesis adalah suatu pertanyaan sementara atau dugaan yang paling memungkinkan yang masih harus dicari kebenarannya. Berdasarkan perumusan masalah, tinjauan pustaka, dan tinjauan penelitian terdahulu dapat ditarik hipotesis pada penelitian ini yaitu :

H1 : Citra merek memiliki pengaruh yang positif terhadap ekuitas merek Hendphone Samsung.

H2 : Kesadaran merek memiliki pengaruh yang positif terhadap ekuitas merek Hendphone Samsung".

\section{METODE PENELITIAN}

Variabel penelitian menurut Sugiyono (2008) adalah suatu atribut atau sifat dari orang, obyek atau kegiatan yang memiliki variasi tertentu yang ditetapkan oleh peneliti untuk dipelajari dan ditarik kesimpulannya. Berkaitan dengan penelitian ini, variabel penelitian yang terdiri dari variabel dependen dan variabel independen, (a). Variabel Dependen yaitu : Y = Ekuitas merek (b). Variabel Independen yaitu : X1 = Citra Merek, X2 = Kesadaran Merek Populasi dari penelitian ini adalah semua konsumen produk susu 
cair dalam kemasan dengan merek "Indomilk" di kota Semarang dan jumlahnya tidak diketahui secara pasti, maka digunakan teknik penentuan jumlah sampel untuk populasi tidak terhingga (Widiyanto, 2008) sebagai berikut :

$$
\mathrm{n}=\frac{\mathrm{Z}^{2}}{4(\mathrm{moe})^{2}}=\frac{1,96}{4(0,1)^{2}}=96,6
$$

Keterangan:

$\mathrm{N}$

$=$ Jumlah sampel

$\mathrm{Z} \quad=$ Tingkat distribusi normal pada taraf signifikansi $5 \%(1,96)$

$$
\begin{aligned}
\text { moe }= & \text { Margin of error } \\
& \text { maksimal, adalah tingkat } \\
& \text { kesalahanmaksimal } \\
& \text { pengambilan sampel yang } \\
& \text { masih bisa ditoleransi yaitu } \\
& 10 \% .
\end{aligned}
$$

Berdasarkan

perhitungan

menggunakan rumus di atas diperoleh jumlah sampel yang bagus minimal sebesar 96,6 yang dibulatkan ke atas menjadi 97 sampel. Namun, nantinya jumlah sampel yang digunakan dalam penelitian ini adalah berjumlah 100 responden.

Pengujian dalam penelitian ini dilakukan dengan cara mencobakan instrumen sekali saja, dan dari data yang diperoleh dianalisis dengan SPSS for Windows 21 yang memberikan fasilitas untuk mengukur reliabilitas dengan uji statistik Cronbach Alpha.
Suatu instrumen dikatakan reliabel jika nilai Cronbach Alpha lebih besar dari 0,6 (Ghozali, 2005) Analisis Angka Indeks, Analisis ini dilakukan untuk mendapatkan gambaran deskriptif mengenai responden penelitian ini, khususnya mengenai variabel-variabel penelitian yang digunakan. Analisis ini dilakukan dengan menggunakan teknik analisis indeks, untuk menggambarkan persepsi responden atas item-item pertanyaan yang diajukan (Ferdinand, 2006).

Angka indeks jawaban responden dapat diperoleh dari hasil output SPSS tentang mean dari masing-masing indikator variabel. Teknik skoring yang dilakukan dalam penelitian ini adalah minimun 0,1 dan maksimum 5 . Dengan menggunakan Three-box Method (Ferdinand, 2006), maka rentang sebesar 4,9 dibagi tiga akan menghasilkan 1,63 yang akan digunakan sebagai dasar interprestasi nilai indeks sebagai berikut :

$$
\begin{array}{ll}
0,1-1,73 & =\text { rendah } \\
1,74-3,37 & =\text { sedang } \\
3,38-5 & =\text { tinggi } \\
\text { Dalam } \quad \text { upaya } & \text { menjawab }
\end{array}
$$
permasalahan dalam penelitian ini maka digunakan analisis regresi linear berganda digunakan untuk menganalisis 
pengaruh antara variabel independen (citra merek dan kesadaran merek) terhadap variabel dependen yaitu ekuitas merek. Rumus matematis dari regresi linear berganda yang umum digunakan dalam penelitian adalah sebagai berikut :

$\mathrm{Y}=\mathrm{a}+\mathrm{b}_{1} \mathrm{X}_{1}+\mathrm{b}_{2} \mathrm{X}_{2}+\mathrm{e}$

Keterangan :

$\mathrm{Y}=$ Ekuitas Merek b1, b2 = Koefisien regresi $\mathrm{x} 1=$ Citra merek $\mathrm{x} 2=$ Kesadaran merek

e $\quad=$ standard error

Persamaan regresi dtentukan dengan menggunakan standardized coefficient beta karena masingmasing koefisien variabel bebas (independen) distandarisasikan lebih dulu agar menghasilkan koefisien yang sama satuannya. Maka garis regresi yang dihasilkan melewati garis origin (titik pusat) sehingga tidak ada konstantanya. Keuntungan dengan menggunakan standardized beta adalah mampu mengeliminasi perbedaan unit ukuran pada variabel independen (Ghozali, 2005).

Dalam pengujian digunakan (a). Uji Goodness of Fit, Ketepatan fungsi regresi sampel dalam menaksir nilai aktual dapat dinilai dengan Goodness of Fit-nya. Secara statistik setidaknya ini dapat diukur dari nilai koefisien determinasi, nilai statistik $\mathrm{F}$ dan nilai statistik t. Perhitungan statistik disebut signifikan secara statistik apabila nilai uji statistiknya berada dalam daerah kritis (daerah dimana Ho ditolak), sebaliknya disebut tidak signifikan bila nilai uji statistiknya berada dalam daerah dimana Ho diterima ( Ghozali, 2005) (b). Uji F digunakan untuk menguji hipotesis nol bahwa koefisien determinasi majemuk dalam populasi, $\mathrm{R}^{2}$, sama dengan nol. Uji signifikansi meliputi pengujian signifikansi persamaan regresi secara keseluruhan serta koefisien regresi parsial spesifik. Uji keseluruhan dapat dilakukan dengan menggunakan statistik F.

Dalam penelitian ini Uji $F$ digunakan untuk mempengaruhi variabel terkait, yaitu apakah variabel X1 dan X2 benar-benar berpengaruh secara bersama-sama terhadap variabel $\mathrm{Y}$. (c). Uji t pada dasarnya menunjukkan seberapa jauh pengaruh satu variabel independen secara individual dalam menerangkan variasi variabel independen (Ghozali, 2005) (d). Koefisien Determinasi $\left(\mathrm{R}^{2}\right)$, pada intinya mengukur seberapa jauh kemampuan model dalam menerangkan variasi variabel 
independen.

Nilai koefisien

determinasi adalah antara nol dan

satu. Nilai $\mathrm{R}^{2}$ yang kecil berarti

kemampuan

variabel-variabel

independen dalam menjelaskan

variasi variabel dependen sangat

terbatas.

\section{HASIL PENELITIAN}

\section{Analisis Regresi Linier Berganda}

Dengan dibantu dengan program SPSS dalam proses penghitungan regresi linier berganda antara variabel bebas terhadap variabel terikat dapat diperoleh hasil pengujian pada tabel 1 berikut ini :

Tabel 1

Persamaan Regresi Linier Berganda

Coefficie ts $^{\mathrm{a}}$

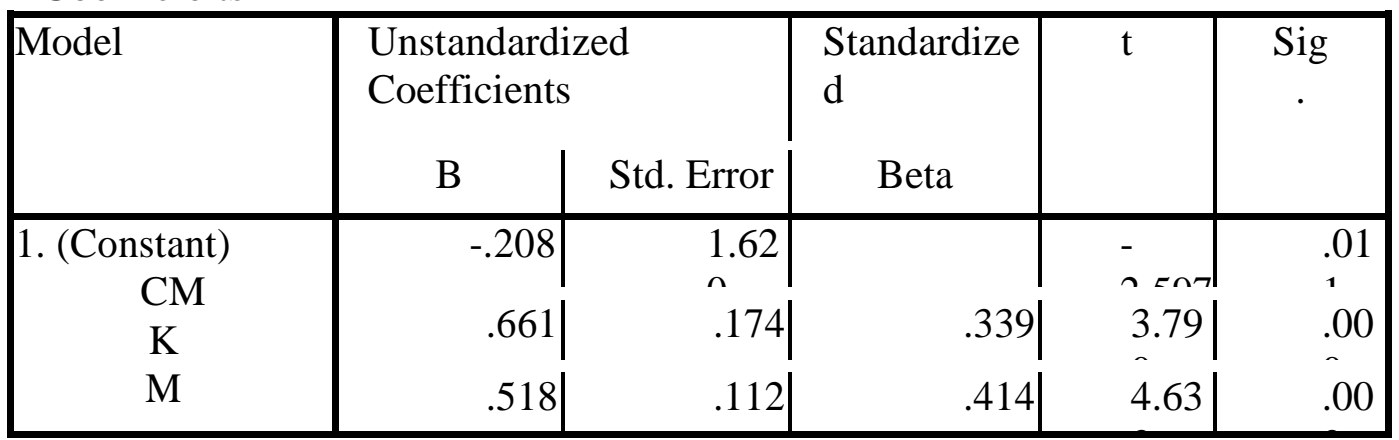

a. Dependent Variable: EM

Sumber : Data primer yang diolah, 2018

Persamaan : Y 0,339X+0,414X

Keterangan:

$\mathrm{Y}=$ ekuitas merek

$\mathrm{X} 1=$ citra merek

$\mathrm{X} 2$ = kesadaran merek

Dari persamaan regresi linier

berganda di atas menunjukan bahwa (1).

Variabel citra merek (X1) memiliki pengaruh yang positif terhadap ekuitas merek (Y) dengan nilai 0,339 (2). Variabel kesadaran merek (X2) memiliki pengaruh yang positif terhadap ekuitas merek (Y) dengan nilai 0,414 .

\section{Uji Goodness of Fit}

Goodness of fit-nya. Secara statistik, setidaknya ini dapat diukur dari nilai statistik t, nilai statistik $F$, dan koefisien determinasinya.

\section{Uji F}

Uji $F$ digunakan untuk menguji ada tidaknya pengaruh variabel-variabel 
independen dengan variabel dependen probabilitas > 0,05 maka Ho diterima secara simultan (bersama-sama). dan jika probabilitas $<0,05$ maka Ho Kriteria yang digunakan adalah, Jika ditolak.

Tabel 2

Hasil Uji Simultan (Uji F)

\begin{tabular}{|c|c|c|c|c|c|c|}
\hline Model & \multicolumn{6}{|c|}{ ANOVA $^{b}$} \\
\hline \multicolumn{2}{|c|}{ Model } & Sum of & $\mathrm{D}$ & Mean & $\mathrm{F}$ & Sig \\
\hline 1 & Regression & 959.38 & 2 & 479.69 & 36.70 & .000 \\
\hline & Residual & 1267.59 & 97 & 13.06 & & \\
\hline
\end{tabular}

a. Predictors: (Constant), KM, CM

b. Dependent Variable: EM

Sumber : Data primer yang diolah, 2018

Berdasarkan hasil uji ANOVA merek (X) secara bersama-sama atau uji $\mathrm{F}$ pada tabel 2 diperoleh berpengaruh secara nyata terhadap fhitung sebesar 36,707 dengan tingkat ekuitas merek (Y).

signifikansi $0,000 . \quad$ Karena nilai

probabilitas $<0,05$ yaitu $(0,000<0,05)$

maka model regresi dapat digunakan

untuk memprediksikan ekuitas merek

\section{Uji t}

Uji statistik $\mathrm{t}$ digunakan untuk (Y) atau dapat dikatakan bahwa variabel citra merek (X1) dan kesadaran

Tabel 3

Hasil Uji t

Coefficients $^{\mathrm{a}}$

\begin{tabular}{|c|r|r|r|r|r|}
\hline Model & \multicolumn{2}{|l|}{$\begin{array}{l}\text { Unstandardized } \\
\text { Coefficients }\end{array}$} & $\begin{array}{l}\text { Standardize } \\
\mathrm{d}\end{array}$ & $\mathrm{t}$ & Sig \\
& $\mathrm{B}$ & Std. Error & & & \\
\hline 1 (Constant) CM & 4.208 & 1.62 & & - & .01 \\
$\mathrm{~K}$ & .661 & .174 & .339 & 3.79 & .00 \\
$\mathrm{M}$ & .518 & .112 & .414 & 4.63 & .00 \\
\hline
\end{tabular}

a. Dependent Variable: EM

mengukur seberapa jauh pengaruh satu variabel independen secara individual dalam menerangkan variasi variabel dependen.

Sumber : Data primer yang diolah, 2018 
Nilai t hitung sebagaimana tersaji dalam tabel 3 di atas, pada variabel citra merek (X1) adalah sebesar 3,790. Karena $\mathrm{t}$ hitung $>\mathrm{t}$ tabel yaitu $(3,790>1,9845)$ dan nilai signifikansi $0,000<0,05$ maka maka Ho ditolak. Kesimpulannya, variabel citra merek secara individual memiliki pengaruh yang positif dan signifikan terhadap ekuitas merek. Nilai t hitung pada variabel kesadaran merek (X2) adalah sebesar 4,633. Karena t hitung > t tabel yaitu $(4,633>1,9845)$ dan nilai signifikansi $0,000<0,05$ maka maka Ho ditolak. Kesimpulannya, variabel kesadaran merek secara individual memiliki pengaruh yang positif dan signifikan terhadap ekuitas merek.

5. Koefisien Determinasi ( $R$ )

Koefisien determinasi $\left(\mathrm{R}^{2}\right)$ pada intinya mengukur seberapa jauh kemampuan model dalam menerangkan variasi variabel independen. Nilai koefisien determinasi adalah antara nol dan satu (Ghozali 2005). Nilai koefisien determinasi $\left(\mathrm{R}^{2}\right)$ dapat dilihat dari tabel 4 berikut ini :

Tabel 4

Koefisien Determinasi (R)

Model Summary

\begin{tabular}{|l|r|r|r|c|}
\hline Model & \multicolumn{1}{|c|}{$\mathrm{R}$} & R Square & $\begin{array}{c}\text { Adjusted R } \\
\text { Square }\end{array}$ & $\begin{array}{c}\text { Std. Error of the } \\
\text { Estimate }\end{array}$ \\
\hline 1 & .656 & .43 & .419 & 3.6149697 \\
\hline
\end{tabular}

a. Predictors: (Constant), CM, KM

Sumber: Data primer yang diolah, 2018

Dari tabel 4 di atas terlihat sebab-sebab yang lain diluar model. tampilan output SPSS model summary besarnya Adjusted R Square adalah 0,419. Hal itu berarti hanya $41,9 \%$ variasi ekuitas merek (Y) dapat dijelaskan oleh variabel-variabel independen di atas. Sedangkan sisanya $(100 \%-41,9 \%=58,1 \%)$ dijelaskan oleh

\section{Interpretasi Hasil}

Pengujian Goodness of Fit, dapat disimpulkan bahwa variabelvariabel independen dalam penelitian ini hanya mampu menerangkan mengenai $41,9 \%$ variasi ekuitas merek 
Hendphone Samsung. Sedangkan sisanya $58,1 \%$ dijelaskan oleh variabel lain yang tidak dimasukan dalam penelitian ini.

Kedua variabel independen yang diuji secara individual yan paling dominan dalam mempengaruhi ekuitas merek hendphone Samsung adalah kesadaran merek dengan koefisien 0,414 . Variabel berikutnya yang memiliki peran yang cukup besar dalam mempengaruhi ekuitas merek Hendphone Samsung adalah citra merek dengan koefisien 0,339. Semua variabel independen dalam penelitian ini memiliki pengaruh yang positif dan signifikan terhadap ekuitas merek Hendphone Samsung.

\section{KESIMPULAN}

Berdasarkan penelitian tentang pengaruh citra merek dan kesadaran merek terhadap ekuitas merek Hendphone Samsung pada 100 responden, maka diperoleh hasil bahwa masing-masing variabel independen yaitu citra merek $\left(\mathrm{X}_{1}\right)$ dan kesadaran merek $\left(\mathrm{X}_{2}\right)$ memiliki pengaruh yang positif dan signifikan terhadap ekuitas merek (Y) Hendphone Samsung. Berdasarkan uji regresi linier berganda variabel kesadaran merek memiliki pengaruh yang paling dominan terhadap ekuitas merek. Selanjutnya berdasarkan analisis angka indeks, indikator dari kesadaran merek yang memiliki nilai indeks paling rendah adalah indikator tentang kemampuan mengenali varian produk (km3) yaitu sebesar 2,458 sehingga dapat disimpulkan bahwa penurunan top brand index merek Hendphone Samsung dan direbutnya posisi pertama dalam top three oleh appel disebabkan oleh faktor konsumen yang masih belum secara sadar mengenali varian produk hendphone Samsung.

\section{DAFTAR PUSTAKA}

Aaker, A. David. 2001. Marketing Research. edisi 7. USA: John Wiley \& Sons

Astuti, Sri Wahjuni dan Cahyadi, I Gde. 2007. Pengaruh Elemen Ekuitas Merek Terhadap Rasa Percaya Diri Pelanggan Di Surabaya Atas Keputusan Pembelian Sepeda Motor Honda. Majalah Ekonomi(ME): Th XVII (2), Agustus 2007

Cahyadi, Rahmad. 1998. Mengukur Ekuitas Merk. Jurnal Ekonomi Bisnis dan Akuntansi, Vol.2

Ferdinand, Augusty. 2006. Metode Penelitian Manajemen. Badan Penerbit Universitas Diponegoro, Semarang

Ghozali, Imam. 2005. Aplikasi Analisis Multivariate dengan Program SPSS. Badan Penerbit Universitas Diponegoro, 
Semarang

Humdiana. 2005. Analisis ElemenElemen Ekuitas Merek

Produk Rokok Merek Djarum

Black. Jurnal Ekonomi

Perusahaan, Vol 12

JRS, Tumpal dan Sitinjak, Tony. 2005. Pengaruh Citra Merek

Dan Sikap Merek Terhadap Ekuitas Merek. Jurnal Ekonomi Perusahaan, Vol 12

Kartajaya, Hermawan. 2006.

Hermawan Kartajaya On

Marketing. Jakarta: PT

Gramedia Pustaka Utama

Knapp , E. Duane . 2001. The

Brand

Mindset.Yogyakarta:

Penerbit Andi

Kotler,

2005.Manajemen

Pemasaran. Ed 11.

Jakarta: Indeks

Kotler, Philip. dan Kevin Lane Keller 2007. Manajemen Pemasaran,

Ed.12. Jakarta: Indeks

Lamb, Charles W, Joseph F. Hair dan

Carl McDaniel. 2001.

Pemasaran. Jakarta: Salemba

Empat

Rajh, Edo. 2005. The Effects of Marketing Mix Elements on Brand Equity. http://www.eizg.hr/AdminLite/FC Keditor/UserFiles/File/CES-83.pdf. Diakses tanggal 15 Maret 2018

Sugiyono. 2008. Metode Penelitian Bisnis. Bandung: Alfabeta

Tony, Sitinjak. 2016. Kinerja Citra, Sikap, dan Ekuitas Merek, kepuasan dan Loyalitas Nasabah Bank BUMN di Jakarta. Juranal Ekonomi perusahaan, Vol. 13

Umar, Husein. 2000. Research

Methods in Finance and

Banking .Jakarta: PT Gramedia

Pustaka Utama
Villarejo, R., Angel F, J. Rondan, F. dan Sanchez, M. J. Direct and Indirect Efffect of Marketing Effort on Brand Awareness and Brand Image. http://www.escpeap.net/conferenc es/marketing/2008_cp/Materiali/P aper/Fr/Villar ejoRamos_RondanCataluna_Sanc hezFranco.pdf. Diakses tanggal 11 Me i 2018

http://www.handiirawan.com diakses $\begin{array}{lll}\text { tanggal } 25 & \text { Februari } 2018\end{array}$ http://www.indofood.com diakses tanggal 26 Maret http://www.indomilk.com/ diakses tanggal 22 Februari 2018 